\title{
New Record of Aspidogaster ijimai Kawamura, 1913 (Trematoda: Aspidogastridae) from Cyprinus carpio in Korea
}

\author{
Dongmin Lee, Hansol Park, Seongjun Choe, Yeseul Kang, Hyeong-Kyu Jeon, Keeseon S. Eom* \\ Department of Parasitology, Medical Research Institute and Parasite Resource Bank, Chungbuk National University School of Medicine,
} Cheongju 28644, Korea

\begin{abstract}
Aspidogastrid trematodes (Subclass Aspidogastrea) are a relatively small group with a characteristic adhesive disc and parasitize in a variety of cold-blooded hosts. Until now, only 2 species in the genus Cotylaspis, i.e., C. coreensis and $C$. sinensis, have been reported as the aspidogastrid trematode in the Republic of Korea (=Korea). In the present study, we intended to describe a species of aspidogastrids collected from the small intestine of the common carp, Cyprinus carpio, in a faunistic point of view. Total 51 specimens were collected from a carp caught in Nakdong-gang (River) on May 2015. Some of them were prepared as the specimens for light microscopic observations, and some others were prepared for SEM. They were slightly elongated without head lobes, 2,432 ×840 $\mu \mathrm{m}$ in average size, and had characteristic adhesive discs with 4 rows and 46 alveoli in average. The ovary was reniform and was located in the posterior-upper part of the body. The single testis was larger than the ovary and was located below the ovary. The uterus was coiled containing numerous eggs and distributed in the posterior $2 / 3$ of the body. The vitellaria were follicular, and distributed from the mid-level of testis to near the posterior end. The morphological characters with dimensions of our specimens were closely identical with those of Aspidogaster ijimai previously described. A new aspidogastrid is added among the Korean trematode fauna by the present study.
\end{abstract}

Key words: Aspidogaster ijimai, carp (Cyprinus carpio), aspidogastrea, new record, Korea

Subclass of Aspidogastrea is the most basal group of trematodes comprising of about 61 valid species distributed worldwide [1]. The aspidogastrid flukes live in cold-blooded animals, like crustaceans, molluscs, fish, and reptiles, as the facultative or obligatory parasites in marine and freshwater environments [2]. Unlike digenean trematodes, they present only a single host to complete their life cycle with no multiplicative larval stages [3]. None of Aspidogastrea has great economic or medical importance, but they have fascinated parasitologists and zoologists for various reasons. For example, the aspidogastrids have very simple life cycles among the trematodes and may therefore be at the root of trematode phylogeny [8]. The most distinctive feature of Aspidogastrea, distinguished from digenean flukes, is having a ventral holdfast organ with rows

- Received 22 February 2017, revised 10 August 2017, accepted 2 September 2017. *Corresponding author (kseom@chungbuk.ac.kr)

(c) 2017, Korean Society for Parasitology and Tropical Medicine

This is an Open Access article distributed under the terms of the Creative Commons Attribution Non-Commercial License (http://creativecommons.org/licenses/by-nc/4.0) which permits unrestricted non-commercial use, distribution, and reproduction in any medium, provided the original work is properly cited. of alveoli or suckerlets, or just presenting a row of rugae or suckers [2].

Only 2 species of aspidogastrid trematodes, i.e., Cotylaspis sinensis and C. coreensis recovered from freshwater mud-turtles, have been reported in Korea [9]. Therefore, we intended to describe a species of aspidogastrids, Aspidogaster ijimai, recovered from the small intestines of the common carp, Cyprinus carpio in Korea. Total 51 worm samples were collected from a common carp from Nakdong-gang in Gumi-si (City), Gyeongsangbuk-do (Province), the Republic of Korea on May 2015. Adult worms were fixed with or without pressure in $10 \%$ formalin. Fixed worms were stored in $70 \%$ ethanol before stain. The specimens were stained with Semichon's acetocarmine for 10 min to $1 \mathrm{hr}$ and then destained to remove excess stain with $1 \%$ acid alcohol, time depending on each specimen. Dehydration and clearing were adopted with a graded ethanol series, 50\% xylene $/ 50 \%$ absolute ethanol, and 100\% xylene before mounting. The specimens were placed under a light microscope, and all organs were measured with a micrometer. Two of the specimens studied have been deposited in the National Institute of 
Biological Resources in Korea (NIBR) with specimen numbers of KOSPIV0000241716 and KOSPIV0000241717.

For scanning electron microscopy (SEM), collected live specimens of A. ijimai were washed thoroughly in $0.8 \% \mathrm{NaCl}$ solution. The parasites were then fixed in $2.5 \%$ aqueous glu-
A

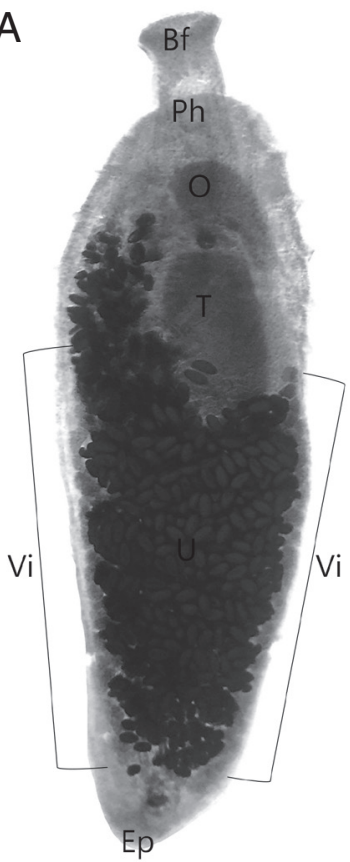

B

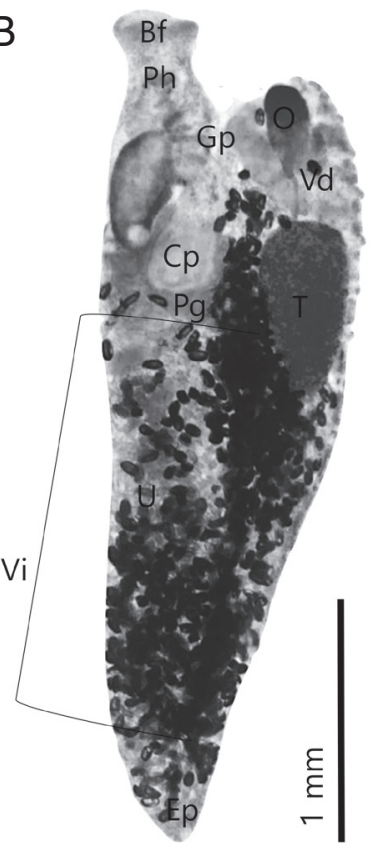

Fig. 1. Aspidogaster ijimai recovered from a common carp, wholemounted. (A) Dorsal view, showing the whole body. (B) Lateral view, Scale bar = $1 \mathrm{~mm}$. Bf, buccal funnel; P, pharynx; Gp, genital pore; O, ovary; Vd, vas deferens; $\mathrm{Cp}$, cirrus pouch; Pg, prostate gland; T, testis; U, uterus; Vi, vitellaria; Ep, excretory pore. taraldehyde for $24 \mathrm{hr}$. The specimens were subsequently dehydrated through a gradient from ethanol to amyl acetate. The specimens were then dipped in hexamethyldisilazane for $1 \mathrm{hr}$, after which they were dehydrated again in a sealed box with silica gel for 1 day. After coating with gold, they were observed by SEM (LEO-15301; Oberkochen, Germany).

\section{Description of Aspidogaster ijimai Kawamura, 1915 (Fig. 1)}

All measurements are in micrometers $(\mu \mathrm{m})$. Body slightly elongated anteroposteriorly, muscular, tapering at both ends, length 2,432 (2,361-2,556), width 840 (796-907). Maximum width recorded at the level of gonads. Typical head lobes absent. The mouth located on anterior margin of the body. Ventral adhesive disc bears 4 longitudinal rows of alveoli and marginal organs. Pharynx large, slightly oval, 148 long and 130 wide, strongly muscular. Intestine simple, with single median tube reaches to near posterior extremity, in large parts covered with uterus. Single testis, elongate and large 611 and 315 , post ovarian. The ovary reniform, 407 and 203. Cirrus-sac present, large, 370 and 213, situated transversely, distal part of sac much narrower than the proximal part. The seminal vesicle and cirrus enclosed in pyriform cirrus pouch. Laurer's canal present. Genital pore at or beyond the level of anterior end of pharynx. Uterus very long, with numerous eggs, fills posterior half of the body, vitellarium follicles rounds, oval, 64 in average length, 37 in average widths, beginning in midline and forming 2 lateral groups in hind body, forms numerous coils. Eggs oval, relatively large, 69 (64-75) long and 44 (34-50) wide.
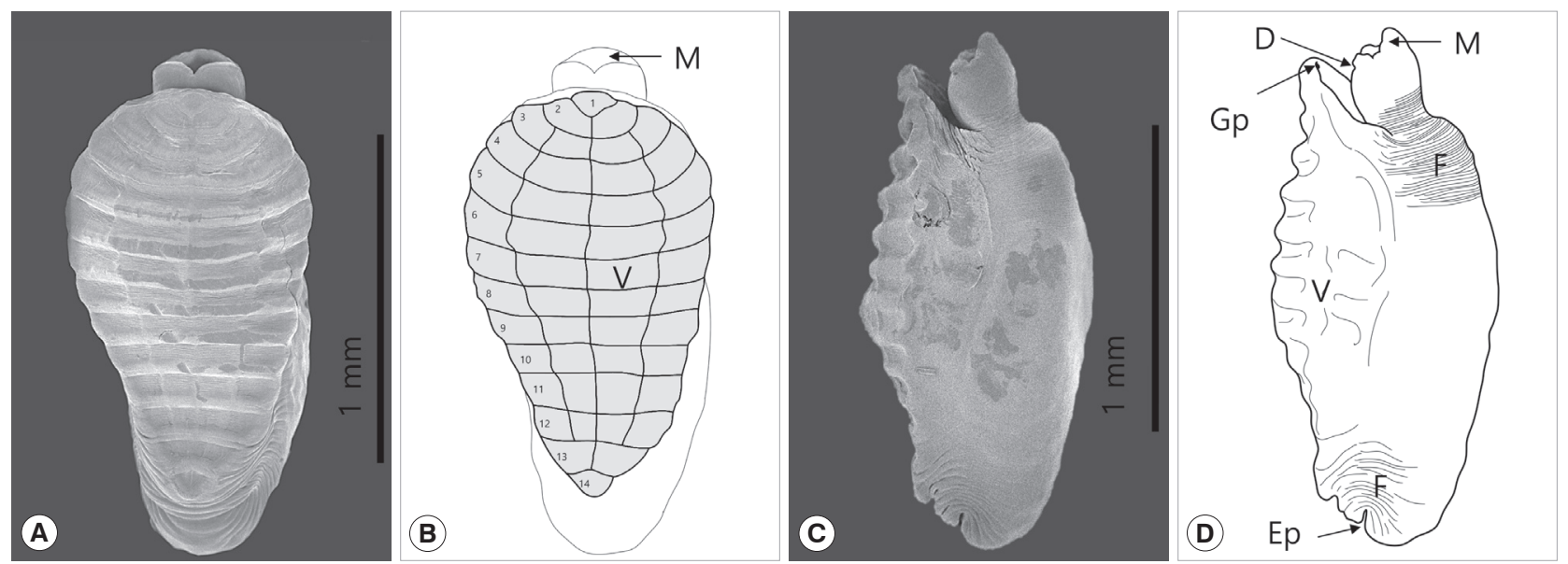

Fig. 2. Aspidogaster ijimai on scanning electron microscopy. (A) Ventral view. (B) Diagram of a dorsal view. (C) Lateral view. (D) Diagram of a lateral view, Scale bar=1 mm. M, mouth; V, ventral disc; D, depression on the ventral part of the neck; F, folds on the dorsal part; Gp, genital pore; Ep, excretory pore. 
The main character of A. ijimai is that the ventral adhesive disc has 4 longitudinal rows of the alveoli encircled by the transverse and longitudinal septa. They have a total 46 alveoli on the entire disk: 14 rows of transverse alveoli and 4 longitudinal rows except for fore and hind 2 rows each. The tegument of the dorsal part of A. ijimai exhibits a series of folds especially at the neck and terminal region, which suggests that the elasticity of both ends of the body is well developed. An excretory pore was observed on the posterior part of the body (Fig. 2).

The genus Aspidogaster species has common characters of single testis, cirrus-sac absent, and head lobes also absent [10]. The morphological characters with dimensions of our specimens were well matched with those of Aspidogaster ijimai described previously $[4,7]$. On observation of the stained specimen, KOSPIV0000241716-7, the left vitellarium of A. ijimai was slightly shorter than the right one, which feature is similar with A. limacoides Diesing, 1835 [6]. Above all, the ventral disk shape can be the main key to distinguish among the carp aspidogastrian species. It could be simply identified according to the number of alveoli; A. ijimai is less than 50, A. limacoides is 50-70, and A. conchicola is 60-100 [10]. The number and arrangement of alveoli had to be confirmed by electron microscopy to determine the species. The depression on the backside of neck which is mentioned as a common feature of the genus Aspidogaster (Gao, 2003) was observed in this study.

Out of 12 species of the genus Aspidogaster, 4 species, i.e., A. conchicola, A. decatis, A. ijimai, and A. limacoides, have C. carpio as their final host as far as the literature are concerned [1]. Our aspidogastrean worms were strongly expected to be one of the 4 species above mentioned. According to geographical information, the probability of A. decatis is lowest because it was recorded just in the Middle East regions like Syria and Israel. At first A. ijimai was found together with A. chonchicola from $C$. carpio in Japan [4]. In addition to these 2 species, A. limacoides was also found in China [1]. This information indicates a possibility of finding another kind of aspidogastrids from carps in Korea.

In this study, A. ijimai was identified for the first time in Korea. It was a feasible discovery geographically because it is also known to distribute in China and Japan. Although the aspidogastrian flukes have been reported with a wide range of bivalve and fish hosts in many other localities [1], A. ijimai, interestingly, was found only in carps as a final host $[4,7]$ and just only in Corbicula fluminea as intermediate host in China, so far [5]. The carp is distributed throughout the Korean Peninsula, and we need to study the prevalences of aspidogastrid species in various water systems on the Korean peninsula. The intermediate host of A. ijimai has not been confirmed in Korea yet. Conclusively, it has been confirmed that A. ijimai exists in the carp from some water systems of Nakdong-gang in Korea. Additional ecological and taxonomical studies are needed on this unique parasite with a taxonomic position within the Class Trematoda of the Korean peninsula ecosystem.

\section{ACKNOWLEDGMENTS}

This work was supported by a grant from the National Institute of Biological Resources (NIBR), which is funded by the Ministry of Environment (MOE) of the Republic of Korea (NIBR no. 2015-02-001). The parasite materials used in this study were provided by the Parasite Resource Bank of Korea of the National Research Resource Center (2015-0000037) of the Republic of Korea.

\section{CONFLICT OF INTEREST}

The authors declare that there are no competing interests regarding the publication of this paper.

\section{REFERENCES}

1. Alves PV, Vieira FM, Santos CP, Scholz T, Luque JL. A checklist of the aspidogastrea (Platyhelminthes: Trematoda) of the world. Zootaxa 2015; 3918: 339-396.

2. Rohde K. Subclass Aspidogastrea Faust \& Tang, 1936. In Gibson DI, Jones A, Bray RA eds, Keys to the Trematoda. vol. 1. London, UK. CABI Publishing Wallingford. 2002, pp 5-14.

3. Rohde K. The aspidogastrea, especially Multicotyle purvisi Dawes, 1941. Adv Parasitol 1972; 10: 77-151.

4. Kawamura T. On two species of Aspidogaster. Dobutsugaku Zasshi 1915; 27: 475-480 (in Japanese).

5. Hao Z. Three species of aspidogastrids from Corbicula fluminea (Müller,1774) in estuary of Jiulong river, South Fujian. Sichuan J Zool 2006; 25: 543-546 (in Chinese).

6. Schludermann C, Laimgruber S, Konecny R, Schabuss M. Aspidogaster limacoides Diesing, 1835 (Trematoda, Aspidogastridae): a new parasite of Barbus barbus (L.) (Pisces, Cyprinidae) in Austria. Ann Naturhist Mus Wien 2005; 106: 141-144.

7. Gao Q, Nie P, Yao WJ. Scanning electron microscopy of Aspidogaster ijimai Kawamura, 1913 and A. conchicola Baer, 1827 (Aspidogastrea, Aspidogastridae) with reference to their fish definitive-host specificity. Parasitol Res 2003; 91: 439-443.

8. Rohde K. The minor groups of parasitic Platyhelminthes. Adv 
Parasitol 1994; 33: 145-234.

9. Cho SY, Seo BS. Studies on the parasitic helminths of Korea IV. Intestinal trematodes from freshwater mud-turtle (Amyda sinensis Wiegmann) with description of new species, Cotylaspis coreensis. Korean J Parasitol 1977; 15: 1-10.
10. Yamaguti S. Classification of the Aspidocotylea, with notes on geographical distribution. In Yamaguti S eds, Systema Helminthum. Vol. IV. Monogenea and Aspidocotylea. New York, USA. Interscience Publishers. 1963, pp 313-326. 